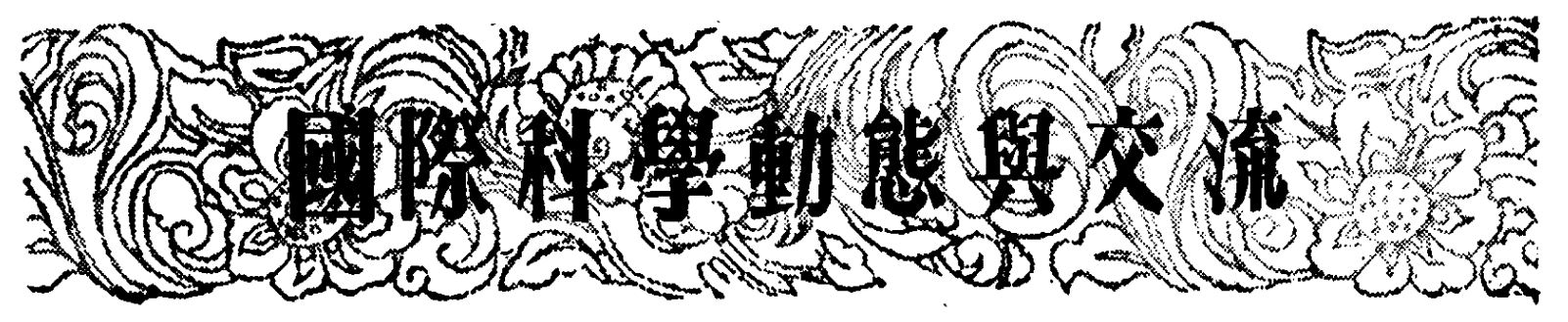

\title{
中樞神經系統在生物免疫過程中所起的作用“
}

\author{
Gr. 本尼荅 托
}

布

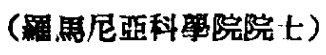

中樞神經系䟽在發生抗微生物的防護作 用 上究竟起一些什窟作用,過去的認識是很少的。近 12 年来, 在克羅什的睢馬尼亞科學院生理學研究 所內, 我們篔經做了許多系統的研究, 罜些研究

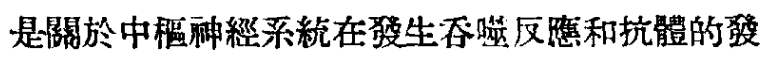
動上所起的作用。

在這研究的第一組裏洦，我們曾經用正常的

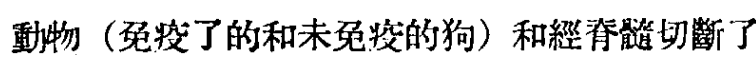
的或是用大劑量的嘘米拿處理過的重物, 研究了 呑嘫反應䫏示的情况, 其中忝嘫活動的测定, 是用 我們的和華德所修改了的苪特的方法。

這個反應是用 100 個白血球（多核白血球） 吞暖鼠型傷寒桿菌的數目來表示的。

根據這些初步的研究, 我們竐楜, 在正常的 動物的靜脈赛注射了沙門氏岿鼠型㑺塞嘲菌3-4

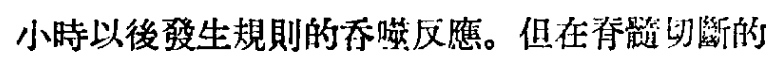

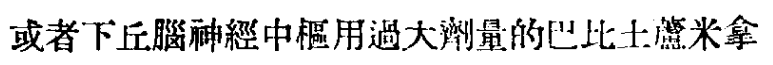
$(0.12$ 公分/公厅）解除了功能的動物內, 這種 反應就完全裂失了。

圖一就是在正常的狗和高級神經中稵用春留造 切斷方法或大剂量的巴比士酸監一類的桨解除了 功能的動物上所得到的結果。

我們看到在正常的動物內，乔㗪活動在產生

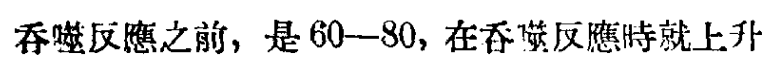
了。上朴的情况在没有免疾的狗队是 $220-300$, 在 預先君疫了的動物內可以值 升到 350-500。

相反的，在脊髓切断了的或是用巴比士酸監 一類的樂處理過了的動物內, 呑嚓反應就没有出
現。 遭個研究的第二組是利用隔離頭部的为法做
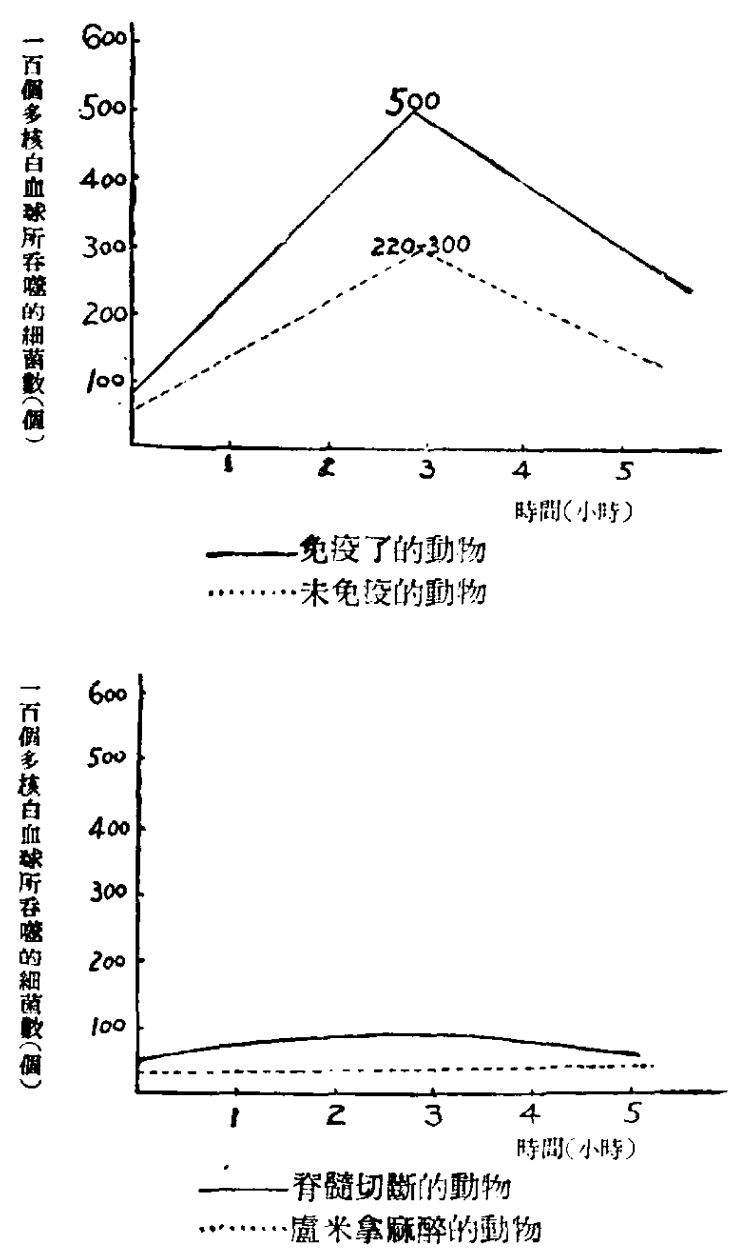

圆一正常及處理過的狗的吞噬反應

- 本交是羅馬尼亞科學院 Gr. 本尼笭托院 卜在我: 國中央衛生研究院的講演稿，詮交未經本尼塔托院 $\mathrm{t}$ 深 查, 內容可能稍有出入。一譯者牲 
的，這個方法是我們自己改良過的，與海曼的方 法完全不同。在我們的方法裹，皮質和脊路以及 和下丘腦脊䯕的通路是完整的。

這個實驗是在网個用氮䤈传游醉了的狗身上 做的。一個是受血者, 它的頭是隔離了的; 另一 個是輸血者。在受血的動物身上, 我們切斷頸部 所有解剖學上的部份, 只留下頸部的脊椎和兩條 迷走交感神經幹。

然後用一個電鑽孔器, 在第二個頸脊椎骨.鑚

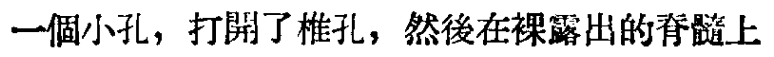

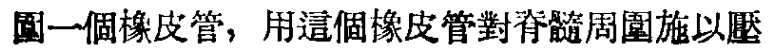
力，這国力等於 40 毫米 水銀柱。(訚二)

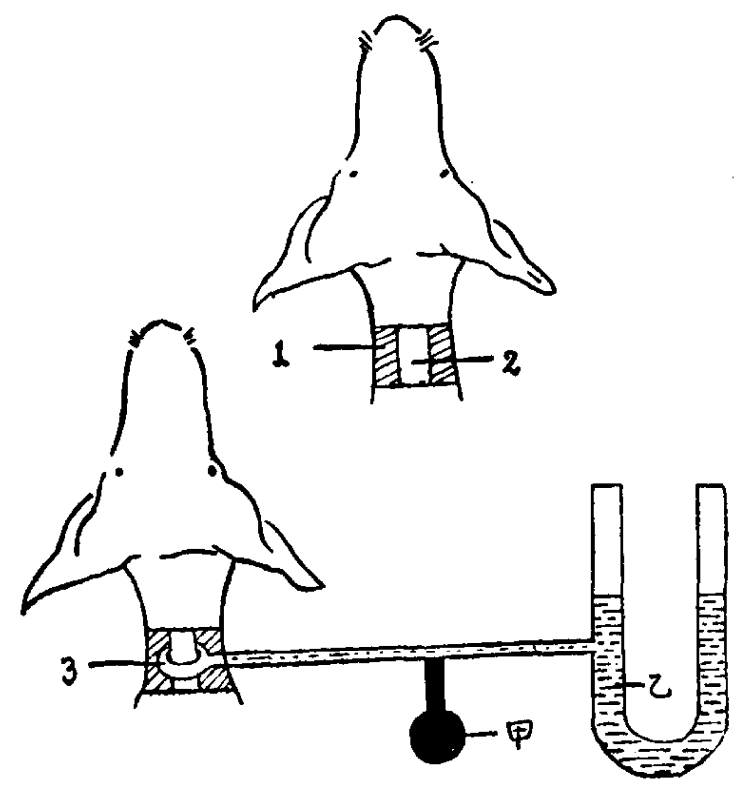

圖二隔離頭部的裝置

1. 截除部分 2. 保留部分: 迷走交感神經幹

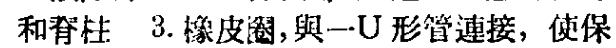
留部分感受䜿力 甲, 橡皮球, 乙, 水銅

我們用派霖晨管方法將受血動物的项動脈和

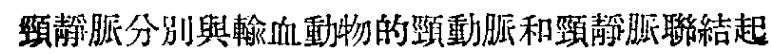

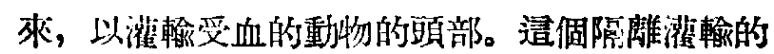
頭部，可以在合適的情况下維持 10-16 小時。在 那㑬時候，受血者的身體能够繼續自動地呼吸， 逆表明奉䯘的功能是完整的。(圖三)

在 10 年之間,我們用隔雐頭部的方法作了很 多的磝究。這些研究證明了我們的技術可以保證 頭部的體液與挋等的體液完全被隔䧸了。因此,

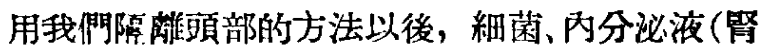
上腺素、大腦㕿體素）和中國墨的小顆粒（直徑 20 毫微米）不能從頭部透過到挋幹裹去。
利用我們的分離頭部的方法，我們會證明那 些細菌（鼠型傷寒桿菌）注射到輸血者身上，毫 無例外地刺激了受血者的高級神經中樞, 並引起 它的吞筷反應。逭個反應很規則地在注射細菌之 後䊏續 $1 \frac{1}{2}-2$ 小時。我們也作了一個反面的證 明, 就是注射細菌到受血者的軀幹裹去。它的躯 幹和它的頭部沟有一切體液的通路, 而在逪個筫 驗情况之下, 呑噬反應也發生了, 但是晚了 9-10 小時。我們也曾表示出, 值接用感應電流揦激下 丘腧部分能引起吞筑反雇。因此, 我們可以認第, 在自然的環境下, 病菌鑽到器官裹去時也刺激神 經中樞, 引起一個反應。這個反應沿着下丘膎到; 延腦的通路引起乔筑反應。

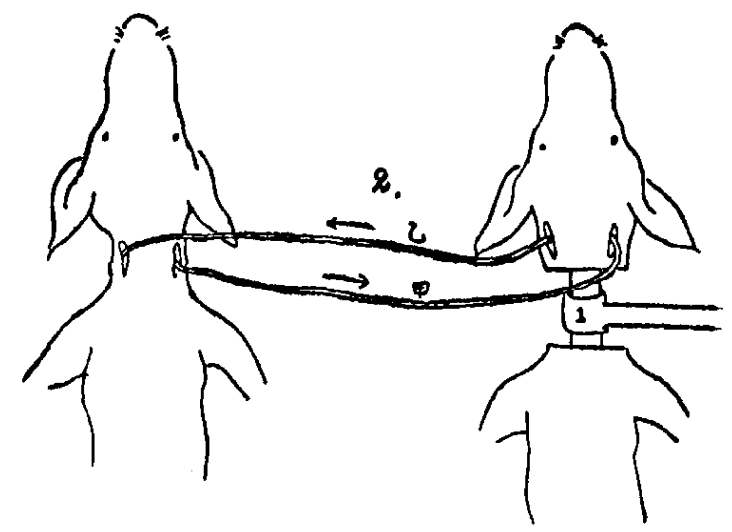

䡆血者

受血者

圖三頭部隔離及灌輸裝置

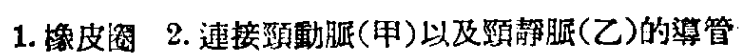

假如我們承認忝噬反應在抗渞保護的作用 上具有更重要的意義，承認這個反應的有效是由 於它的迅速性，承認選個反應的迅速性是由於高 級神經中樞的分楩所規定的，那密，我們就可以 了解中樞神經系統在保護作用上的意義。

在續我們的閣於生物炛疫過程中柿經系紿. 內所起的作用的研究上，我們辽做了一些關於抗 體的形成裏中樞种經系統的作用的筫驗。可是遖 到現在篇止，我們僈不能得到任何證據證明中樞 神經系統也參加在抗體的形成裹面。

相反的, 在預先災㾤過了的狗的試驗上, 我

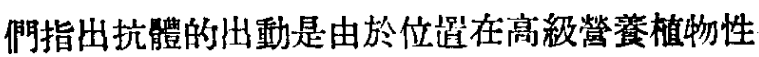
器官中樞的中樞神經的機構。

最後, 我們要搞清楚, 這些器官是在下丘腦

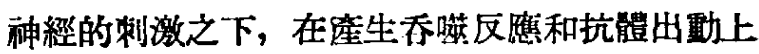
起了中間的作用。

\section{5 月號}


我們䁌做另外一系列的許多試騟，在這些試 数复, 都利用了一個技術。这個技街就是應用一

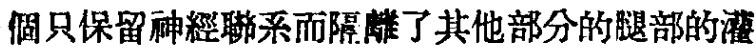
輸裝管。在右頸氣管分枝處和胸管各作了瘦管, 把全部淋巴産物放到生物體外去。

這樣，我們就可以指出，抗體的出動，是由 所有的淋巴組織所做的。

至於談到吞唡制激的物質是如何座生的，我 們的研究指出, 所有的富於絧狀队佊組織的器官

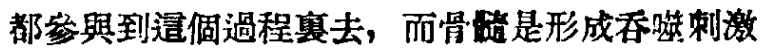
物質的最重要的器官。

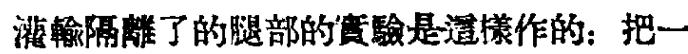
隻狗的腿部的循環系統和身體隔離, 但是保留完 整的坐骨神經。逼隻狗的血液供給是由另一隻狗 的经動脈和頸靜胍與造隻狗腿的動静脈聯系而循

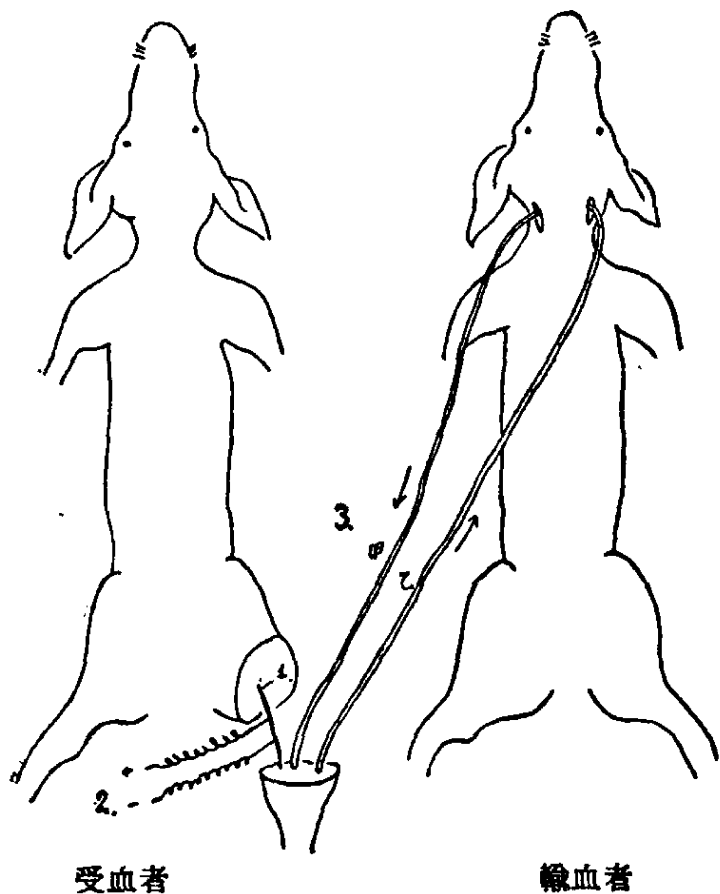

圆四腿部隔離與灌輸裝置

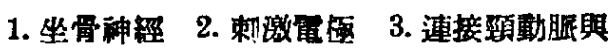

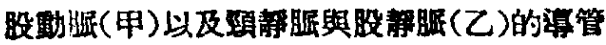

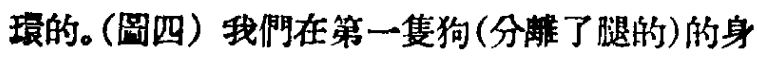

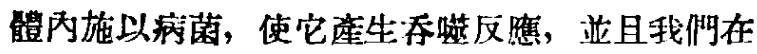

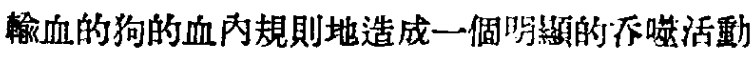
的高潮。

仔細的分析後，我們可以說暗個效果是由於

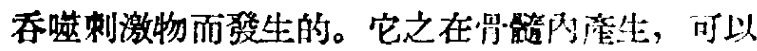
在脛骨的靜眼內證賽。同樣地，在用電剌湤了坐

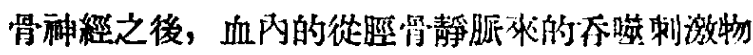
就增加 500-800\%。

造样, 我們可以看出造是第一一次我們可以談 到神經的忝哑刺激作用。在我們的工作的最後一 部分中, 我們研究了大腦皮質在生物㣻疫過程赛

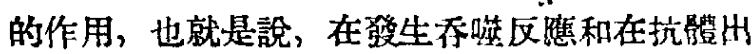
動上的作用。在這個目的上，我們聯系了一個特 殊的興套活動, 就是說鈴馨與施用疗葆聯系起來。

一個月之後，只要鈴馨一響，由於條件反射的機 構，在這個詰驗裏所有的狗（6隻）身上我門都 得到 200-300\% 的乔哑反應和一次抗體的出動。

12 年来的研究, 總結出在生物琶疾的過 程

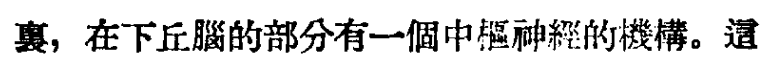
機構能使所有的預先仔在的保護方法活動起來。

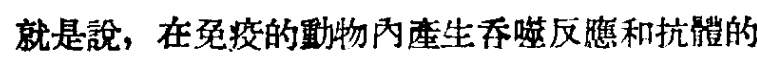
出動。

大腦皮雷也能參與到這個機構裹。可是'它的 参與不是必須的，因此，我椚看到，在生物免

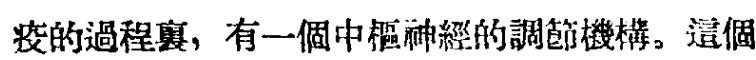
機構可以認第是機體對於㻴境裹生物因絭變化的 適應的生理反應, 這些反應和對物理团絭的適應

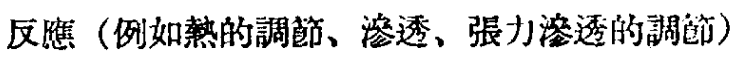
是完全相似的。我們的砷究的結果是在世求洛夫 的新的概念範園赛。根據他的概念, 中秒㬏經系 梳在所有的器官活動的調協與和諧上起了很重要 的作用的。在機體對外界環境的䢛㫿上,也起了很 重要的作用。

\section{“辟爾當 人”的秘密}

辟爾當人 (Piltdownman) 或道生 氏暗人 (Dawson's downman) 曾否员正存在罜一問 题，是四十餘年來人類進化史上的一件疑案，㯰

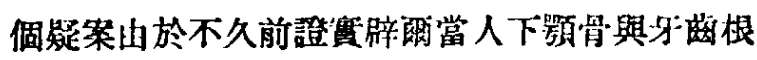
本是傦造的而得到了解决。英國工人日報於 1953 年11月23日、24日報道了這件事情。 